\title{
Evaluation of Traumatic Knee and Shoulder Joint Ligaments with MRI among Adult Sudanese Patients
}

\author{
Shaza Mahgoub Masaad, $\mathrm{MSc}^{1}$; Mohamed Yousef, $\mathrm{PhD}^{2}$; Hanady Elyas Osman, $\mathrm{PhD}^{1,3}$; \\ Mustafa Z. Mahmoud, $\mathrm{PhD}^{4 *}$ \\ ${ }^{1}$ Faculty of Radiological and Nuclear Medicine Science, The National Ribat University, Khartoum, Sudan \\ ${ }^{2}$ Radiologic Sciences Program, Batterjee Medical College, Jeddah, Saudi Arabia \\ ${ }^{3}$ Medical Imaging Technology Department, Al-Ghad International College for Applied Medical Science, \\ Jeddah, Saudi Arabia \\ ${ }^{4}$ Radiology and Medical Imaging Department, College of Applied Medical Sciences, \\ Prince Sattam bin Abdulaziz University, Al-Kharj, Saudi Arabia
}

\begin{abstract}
Background: Magnetic resonance imaging (MRI) is currently regarded as the reference standard for the diagnosis and evaluation of internal derangements of the knee and shoulder girdle. This study aimed to evaluate traumatic injuries of the knee and shoulder joint ligaments by MRI and classify the most common ligament injuries.

Methods and Results: This study included 50 patients, who were presented in the Radiology Department of Modern Medical Center in Khartoum, in the period from October 2019 to January 2020. The sample was divided into two groups: shoulder joint group (Group 1, n=30) with an age range between 16 and 74 years and knee joint group (Group 2, n=20) with an age range between 16 and 77 years. The age group most affected with shoulder (46.7\%) and knee joint (25\%) injuries was 46-65 years. The injuries of the shoulder (40\%) and knee joints (55\%) were common in patients with body weight ranging from 71-80 kg and $>81 \mathrm{~kg}$, respectively. Different grades of partial meniscus tear of both shoulder and knee joints were noted as Grades 1 and 2 in $8.7 \%$ of cases, Grade 2 $13 \%$, Grades 2 and $3-34.8 \%$, and Grade $3-30.4 \%$. There were incidences of $27.3 \%, 0 \%, 54.5 \%, 15.20,0 \%$, and $3 \%$ for anterior cruciate ligament, posterior cruciate ligament, medial meniscus C-shape (M Me C), lateral meniscus C-shape (L Me C), medial collateral ligament, and lateral collateral ligament tears in the knee joints of the affected patients.

Conclusion: MRI revealed that injuries to the shoulder and knee joints were common in patients with body weight ranging from 71-80 kg and $>81 \mathrm{~kg}$, respectively. Different grades of partial meniscus tear of the shoulder and knee joints were noted though Grades 2 and 3 partial tears were the most common finding. Finally, it was noted that in the knee joints of the affected patients, the M Me C shaped tear was the major type of tear.(International Journal of Biomedicine. 2020;10(4):387-391.)
\end{abstract}

Key Words: magnetic resonance imaging $\bullet$ shoulder girdle $\bullet$ knee joint injuries $\bullet$ medial meniscal cartilage

\section{Abbreviations}

MRI, magnetic resonance imaging; AGL, anterior glenoid labral; MMC, medial meniscal cartilage; LCL, lateral collateral ligament; MCL, medial collateral ligament; ACL, anterior cruciate ligament; PCL, posterior cruciate ligament.

\section{Introduction}

The use of MRI has become a routine examination in evaluating and diagnosing musculoskeletal diseases. Nowadays, MRI is used as a preoperative planning method for patients thought to have surgical diseases based on history and physical examination. ${ }^{(1)}$
The knee and shoulder joints are the largest joints of the musculoskeletal system, with complex articulation characterized by the presence of a group of ligament and tendon cartilages, and meniscus structures, that play an important role in stability and mobility. MRI is currently regarded as the reference standard for the diagnosis and evaluation of internal derangements of the knee and shoulder girdle. Due to 
its excellent soft-tissue enhancement and multiplanar imaging capabilities, MRI provides significant advantages over other imaging techniques in the evaluation of traumatic injuries of knee and shoulder joints. ${ }^{(2)}$ Ligaments and tendons in both joints provide support and stability to the joints. They allow a normal movement of the joint and any abnormal defect or stress that would render the joint unstable or lead to diseases.

(3) When a football player catches his foot in the turf and his whole body weight goes over one joint, this leads to overstress in that joint and this force produces structural damage to the joint structure and ligaments, which is known as a ligament injury. ${ }^{(4)}$

MRI has high diagnostic performance in the evaluation and assessment of musculoskeletal soft tissue injuries. Nowhere is this more accurate than in the evaluation of the internal structure of joints. MRI is an accurate and cost-effective tool for characterizing a wide spectrum of joint injuries, ranging from ligament injuries to cartilage deficiencies. ${ }^{(5)}$ For radiologists and physicians, evaluation of an injured ligament using MRI requires knowledge of the proper imaging techniques and appropriate protocol, normal and abnormal anatomy, and the clinical significance of detecting abnormalities in the joint. ${ }^{(6)}$

An optimal MRI technique should include proper patient position, dedicated surface coils, gradient coils, and specific protocols for the suspected diseases. MRI is a powerful method for diagnosing acute and chronic lesions of the stabilizing articular elements and is also useful for evaluating traumatic conditions of the tendons. In normal MRI exams, ligaments and tendons have low signal intensity on MR images, whereas disruption manifests as increased or high signal intensity. Radiologists must be sufficiently aware and possess the expertise to understand the full spectrum of ligament abnormalities and associated MRI findings. ${ }^{(7)}$

MRI allows optimal diagnosis and evaluates the presence of a tear in the joint, the number of an affected ligament or tendon retraction, and the presence of associated lesions. This information is used to decide the correct surgical plan and surgical approach. ${ }^{(8)}$ Thus, this study aimed to evaluate traumatic injuries of the knee and shoulder joint ligaments by MRI and classify the most common ligament injuries.

\section{Materials and Methods}

This study included 50 patients, who were presented in the Radiology Department of Modern Medical Center in Khartoum, in the period from October 2019 to January 2020. The current study adhered to the Declaration of Helsinki and Title 4, US Code of Federal Regulations, Part 46, Protection of Human Subjects.

The sample was divided into two groups: shoulder joint group (Group 1, $\mathrm{n}=30$ ) with an age range between 16 and 74 years and knee joint group (Group 2, n=20) with an age range between 16 and 77 years.

A waiver of informed consent was conceded as per institutional rules. The inclusion criteria were adult patients with signs and symptoms of ligament tears or musculoskeletal disease in shoulder and knee joints.
Shoulder and knee MRI exams were conducted using General Electric (GE) Signa HD 1.5T MRI scanner (Boston, USA) with an aperture diameter of $60 \mathrm{~cm}$. MRI Linux software as an operating system and GE application program. Imaging the shoulder is optimal with a dedicated shoulder coil HD phase array, earplugs to reduce coil noise, and immobilization straps and pads. The patient was in a supine position and careful positioning with the shoulder as close to the center of the magnet as possible. Basic routine sequences are $T_{1}$-weighted image $-T_{1} W$ spin echo ( $S E$ ), $\mathrm{T}_{1}$-weighted fast spin echo (FSE), and proton density (PD) fat saturated image (fat-sat) and oriented with axial and coronal orientation in conjunction with coronal, oblique PD FSE fat-sat and sagittal $T_{2}$ FSE. To visualize the bicep tendon, labrum, and subscapularis tendon in the shoulder joint, the axial $\mathrm{T}_{2}$ FSE gradient-recalled echo is a sequence of choice. If the radiologist hesitated about any findings, the short- $\mathrm{T}_{1}$ inversion recovery in coronal and axial plane was used. The optimal field of view for shoulder and knee MRI examination was $14 \times 16 \mathrm{~cm}$, slice thickness $3.5-4 \mathrm{~mm}$ and matrix of $512 \times 512$. $^{(7,8)}$

Imaging the knee is optimal with a coil HD phase array, earplugs, and immobilization pads. The patient lies in a supine position on the couch and the knee is placed within the coil and well immobilized with foam pads. The patient is positioned so that the longitudinal alignment light lies either along the midline of the leg under examination, or displaced from it if the knee has been offset. The knee MRI basic sequences are $\mathrm{T}_{1} \mathrm{SE}$, $\mathrm{T}_{2}$ FSE, and PD FSE fat-sat oriented with sagittal and coronal orientation in conjunction with coronal $\mathrm{T}_{2}$ FSE fat-sat for best visualization of the LCL and MCL. Sagittal $T_{2}$ FSE fat-sat is used for the best visualization of the ACL and PCL. Additional information is initiated by applying a special pulse sequence of STIR in the sagittal and coronal plane. ${ }^{(7,8)}$

In addition, an abnormal high signal intensity in the menisci of the knee and shoulder joint was placed into three broad categories that indicate a partial tear, according to Lotysch et al. ${ }^{(9)}$ A Grade 1 signal is a rounded or amorphous signal in the meniscus that does not disrupt an articular surface. A Grade 2 signal is a linear signal that does not disrupt an articular surface. Grades 1 and 2 signals have been shown to be due to intrasubstance degeneration of the meniscus. ${ }^{(10)}$ A Grade 3 signal is a signal that disrupts an articular surface and indicates a meniscal tear.

Statistical analysis was performed using the standard Statistical Package for the Social Sciences (SPSS Inc., Chicago, IL, USA) version 20 for windows.

\section{Results}

In the current study, participants were divided into four age groups $(<25,26-45,46-65$, and $>65$ years). The age group most affected with shoulder (46.7\%) and knee joint $(25 \%)$ injuries was 46-65 years (Table 1).

The majority of the patients were males. Their weight ranged from $<60 \mathrm{~kg}$ up to $>81 \mathrm{~kg}$. The weight of $40 \%$ of cases ranged from $71-80 \mathrm{~kg}$ while the weight of $6.6 \%$ was $<60 \mathrm{~kg}$. The injuries of the shoulder (40\%) and knee joints (55\%) were 
common in patients with body weight ranging from $71-80 \mathrm{~kg}$ and $>81 \mathrm{~kg}$, respectively (Table 2 ).

Table 3 summarizes the frequency and the percentage of the most affected side in the examined joints. It was found that the left shoulder joint was affected in $18(60 \%)$ patients while the right knee joint was affected in 11(55\%) patients.

\section{Table 1.}

Distribution of traumatic injuries of the knee and shoulder joint ligaments in different age groups

\begin{tabular}{|c|c|c|c|c|}
\hline \multirow{2}{*}{$\begin{array}{c}\text { Age } \\
\text { group } \\
\text { (years) }\end{array}$} & \multicolumn{2}{|c|}{ Shoulder joint injuries } & \multicolumn{2}{c|}{ Knee joint injuries } \\
\cline { 2 - 5 } & Frequency & Percentage (\%) & Frequency & Percentage (\%) \\
\hline$<25$ & 3 & $10 \%$ & 4 & $20 \%$ \\
\hline $26-45$ & 7 & $23.3 \%$ & 7 & $35 \%$ \\
\hline $46-65$ & 14 & $46.7 \%$ & 5 & $25 \%$ \\
\hline$>65$ & 6 & $20 \%$ & 4 & $20 \%$ \\
\hline
\end{tabular}

Table 2.

Distribution of traumatic injuries of the knee and shoulder joints, according to body weight

\begin{tabular}{|c|c|c|c|c|}
\hline \multirow{2}{*}{$\begin{array}{c}\text { Weight } \\
(\mathrm{kg})\end{array}$} & \multicolumn{2}{|c|}{ Shoulder joint } & \multicolumn{2}{c|}{ Knee joint } \\
\cline { 2 - 5 } & Frequency & Percentage (\%) & Frequency & Percentage (\%) \\
\hline$<60$ & 2 & $6.6 \%$ & 1 & $5 \%$ \\
\hline $61-70$ & 8 & $26.7 \%$ & 4 & $20 \%$ \\
\hline $71-80$ & 12 & $40 \%$ & 4 & $20 \%$ \\
\hline$>81$ & 8 & $26.7 \%$ & 11 & $55 \%$ \\
\hline
\end{tabular}

Table 3.

The frequency and the percentage of the most affected side in the examined joints

\begin{tabular}{|c|c|c|c|c|}
\hline \multirow{2}{*}{$\begin{array}{c}\text { Affected } \\
\text { side }\end{array}$} & \multicolumn{2}{|c|}{ Shoulder joint } & \multicolumn{2}{c|}{ Knee joint } \\
\cline { 2 - 5 } & Frequency & Percentage (\%) & Frequency & Percentage (\%) \\
\hline Left & 18 & $60 \%$ & 9 & $45 \%$ \\
\hline Right & 12 & $40 \%$ & 11 & $55 \%$ \\
\hline Both & 0 & 0 & 0 & 0 \\
\hline
\end{tabular}

Different grades of partial meniscus tear of both shoulder and knee joints were noted as Grades 1 and 2 in $8.7 \%$ of cases, Grade $2-13 \%$, Grades 2 and $3-34.8 \%$, and Grade $3-30.4 \%$ (Table 4).

Finally, there were incidences of $27.3 \%, 0 \%, 54.5 \%$, $15.20,0 \%$, and $3 \%$ for ACL, PCL, medial meniscus C-shape (M Me C), lateral meniscus C-shape (L Me C), MCL, and LCL tears in the knee joints of the affected patients (Fig.1)
Table 4.

Complete and different grades of partial meniscus tear of both shoulder and knee joints

\begin{tabular}{|l|c|c|}
\hline \multicolumn{1}{|c|}{ Findings } & Frequency & Percentage \\
\hline Complete tear & 3 & $11.5 \%$ \\
\hline Partial tear & 23 & $88.5 \%$ \\
\hline Partial tears, Grades 1 and 2 & 2 & $8.7 \%$ \\
\hline Partial tears, Grade 2 & 3 & $13 \%$ \\
\hline Partial tears, Grades 2 and 3 & 8 & $34.8 \%$ \\
\hline Partial tears, Grade 3 & 7 & $30.4 \%$ \\
\hline
\end{tabular}

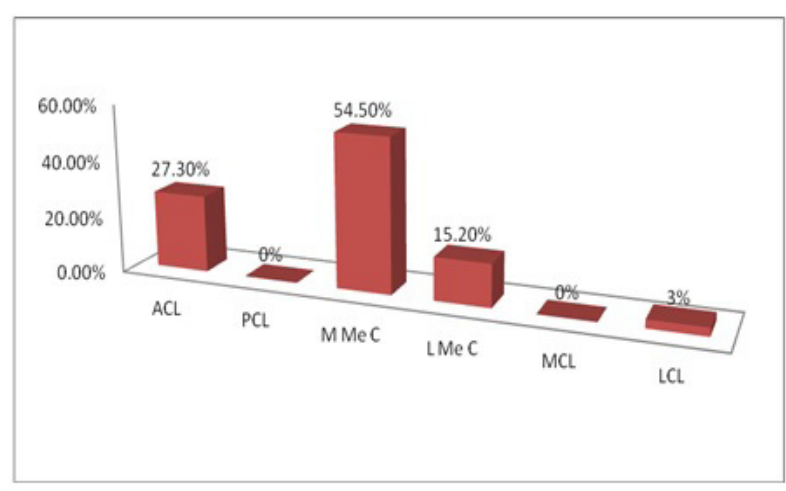

Fig. 1. Incidence of knee joint ACL, PCL, M Me C shape, $L M e C$ shape, $M C L$, and LCL tears.

\section{Discussion}

Several imaging modalities, including nuclear medicine, ultrasound, computerized tomography, and MRI, have been used in an attempt to provide a pathophysiological diagnosis in patients with shoulder or knee ligament injuries. The diagnosis of shoulder and knee ligament injuries and diseases has been complicated, so aside from radiological investigations, those modalities guide us to some types of diagnosis and planning. MRI is the method of choice for the routine measurement of shoulder ligament injuries. . $^{(4,11,12)}$

The findings of the current study were compatible with Dinnes et al., ${ }^{(4)}$ who conclude that in 29 cohort studies there were full-thickness tears. In addition, it was found that the overall MRI sensitivities and specificities were high, and in these studies there were partial-thicknesses detected with MRI in rotator cuff tears, where the supraspinatus tendon was one of this group. Furthermore, two studies suggested that magnetic resonance arthrography might give a more accurate detection of full-thickness rotator cuff tears and shoulder joint injuries. ${ }^{(4,11)}$

It was found that $3(11.5 \%)$ of the patients were presented with a complete menisci tear and $23(88.5 \%)$ were presented with a partial meniscus tear. Different grades of partial meniscus tear of both shoulder and knee joints were noted as Grades 1 and 2 in $8.7 \%$ of cases, Grade $2-13 \%$, 
Grades 2 and $3-34.8 \%$, and Grade $3-30.4 \%$. These findings were compatible with the findings of Mietchen et al. ${ }^{(13)}$ and Englund et al. ${ }^{(14)}$

Regarding our results shown in Table 1, it should be noted that a Grade 3 signal was most common in both menisci, followed by Grade 2 and Grade 1, which corresponded to studies done by Kanal et al. ${ }^{(7)}$ and Drapé et al. ${ }^{(1)}$ Among menisci, the medial meniscus is most commonly injured (38\%), followed by the lateral meniscus (26\%). The posterior horn of the medial meniscus was a commonly injured structure among menisci noted in 30 cases out of 64 meniscal tears. The next commonly injured structure is the posterior horn of the lateral meniscus (16.7\%), followed by the anterior horn of the lateral meniscus (14.1\%), the body of the medial meniscus $(12.8 \%)$, the body of the lateral meniscus $(7.7 \%)$, and the anterior horn of the medial meniscus $(2.5 \%)$. Furthermore, some of the tears that were located in one part extended to other parts of the meniscus. The horizontal tear $(12 \%)$ was commonest, followed by a complex tear (11\%), bucket handle tear $(7 \%)$, radial tear $(3 \%)$, and longitudinal tear $(2 \%)$ in the medial meniscus. ${ }^{(15,16)}$

In study by Jarvick et al., ${ }^{(16)}$ the commonest type of tear in the lateral meniscus was a horizontal tear (42.3\%), followed by a complex tear $(26.9 \%)$, longitudinal tear $(15.5 \%)$, vertical radial tear $(11.5 \%)$, and oblique tear $(3.8 \%)$. A similar meniscal injury pattern observed in the present study was comparable to the study of Drapé et al., ${ }^{(11)}$ in which the most common meniscal injury is the posterior horn of the medial meniscus.

Jarvick et al. ${ }^{(16)}$ and Singh et al. ${ }^{(17)}$ found that among meniscal injuries, medial meniscal tears $(46.5 \%)$ were more common than lateral meniscus tears $(37.2 \%)$, and the posterior horn of the medial meniscus (55\%) was the most common site of involvement

Finally, findings presented in Table 4 and Fig. 1 of this study could be compared with the findings of Singh et al. ${ }^{(17)}$ and Gupta et al. ${ }^{(18)}$ Those researchers found in two studies $(\mathrm{n}=100$ patients) that a complete MCL tear was noted in one patient, a partial tear in three patients, and a Grade 1 sprain in one patient. Similarly, a partial LCL tear was noted in three patients and a Grade 1 sprain in three patients. It was found that an MCL injury is associated with ACL and medial meniscus injuries. Out of nine MCL injuries, ACL and medial meniscus injuries were noted in six and two patients, respectively. The O'Donoghue triad was noted in one patient. Three lateral meniscal tears were noted in a total of twelve partial LCL tears. LCL tears showed a relationship with lateral meniscus tears.

Regarding the limitations, this study is limited by the heterogeneity of the population because of the randomized selection process, which may influence the exactness of our outcomes and lessen the certainty of our conclusions.

\section{Conclusion}

the most affected age group with shoulder and knee joint injuries was 46-65 years. MRI revealed that injuries to the shoulder and knee joints were common in patients with body weight ranging from $71-80 \mathrm{~kg}$ and $>81 \mathrm{~kg}$, respectively.
Different grades of partial meniscus tear of the shoulder and knee joints were noted though Grades 2 and 3 partial tears were the most common finding. Finally, it was noted that in the knee joints of the affected patients, the $\mathrm{M} \mathrm{Me} \mathrm{C}$ shaped tear was the major type of tear.

\section{Acknowledgments}

This publication was supported by the Deanship of Scientific Research at Prince Sattam bin Abdulaziz University, Alkharj, Saudi Arabia.

\section{Competing Interests} interests.

The authors declare that they have no competing

\section{References}

1. Kinkade S. Evaluation and treatment of acute low back pain. Am Fam Physician. 2007 Apr 15;75(8):1181-8.

2. Vaz CE, Camargo OP, Santana PJ, Valezi AC. Accuracy of magnetic resonance in identifying traumatic intraarticular knee lesions. Clinics (Sao Paulo). 2005 Dec;60(6):445-50.

3. Borthakur A, Mellon E, Niyogi S, Witschey W, Kneeland JB, Reddy R. Sodium and T1rho MRI for molecular and diagnostic imaging of articular cartilage. NMR Biomed. 2006 Nov;19(7):781-821. doi: 10.1002/nbm.1102.

4. Dinnes J, Loveman E, McIntyre L, Waugh N. The effectiveness of diagnostic tests for the assessment of shoulder pain due to soft tissue disorders: a systematic review. Health Technol Assess. 2003;7(29):iii, 1-166. doi: 10.3310/hta7290.

5. Rubin DA, Kneeland JB, Kitay GS, Naranja RJ Jr. Flexor tendon tears in the hand: use of MR imaging to diagnose degree of injury in a cadaver model. AJR Am J Roentgenol. 1996 Mar;166(3):615-20. doi: 10.2214/ajr.166.3.8623637.

6. Muhle C, Ahn JM, Dieke C. Diagnosis of ACL and meniscal injuries: MR imaging of knee flexion versus extension compared to arthroscopy. Springerplus. 2013 May 8;2(1):213. doi: 10.1186/2193-1801-2-213.

7. Kanal E, Barkovich AJ, Bell C, Borgstede JP, Bradley WG Jr, Froelich JW, Gilk T, Gimbel JR, Gosbee J, Kuhni-Kaminski E, Lester JW Jr, Nyenhuis J, Parag Y, Schaefer DJ, SebekScoumis EA, Weinreb J, Zaremba LA, Wilcox P, Lucey L, Sass N; ACR Blue Ribbon Panel on MR Safety. ACR guidance document for safe MR practices: 2007. AJR Am J Roentgenol. 2007 Jun;188(6):1447-74. doi: 10.2214/AJR.06.1616.

8. Budinger TF, Fischer H, Hentschel D, Reinfelder HE, Schmitt F. Physiological effects of fast oscillating magnetic field gradients. J Comput Assist Tomogr. 1991 NovDec;15(6):909-14. doi: 10.1097/00004728-199111000-00001. 9. Lotysch M, Mink J, Crues JV, Schwartz SA. Magnetic resonance imaging in the detection of meniscal injuries (Oral abstract). Magn Reson Imaging. 1986;4(2):185. doi:

*Corresponding author: Professor Mustafa Z. Mahmoud, Radiology and Medical Imaging Department, College of Applied Medical Sciences, Prince Sattam bin Abdulaziz University, E-mail: m.alhassen@psau.edu.sa, PO Box: 422, Zip Code: 11942, Al-Kharj, Saudi Arabia. 
10.1016/0730-725X(86)91028-3

10. Stoller DW, Martin C, Crues JV 3rd, Kaplan L, Mink JH. Meniscal tears: pathologic correlation with MR imaging. Radiology. 1987 Jun;163(3):731-5. doi: 10.1148/ radiology.163.3.3575724.

11. Drapé JL, Tardif-Chastenet de Gery S, SilbermannHoffman O, Chevrot A, Houvet P, Alnot JY, Benacerraf R. Closed ruptures of the flexor digitorum tendons: MRI evaluation. Skeletal Radiol. 1998 Nov;27(11):617-24. doi: $10.1007 / \mathrm{s} 002560050447$.

12. Gusmer PB, Potter HG, Schatz JA, Wickiewicz TL, Altchek DW, O'Brien SJ, Warren RF. Labral injuries: accuracy of detection with unenhanced MR imaging of the shoulder. Radiology. 1996 Aug;200(2):519-24. doi: 10.1148/ radiology.200.2.8685350.

13. Mietchen D, Aberhan M, Manz B, Hampe O, Mohr B, Neumann C, Volke F. Three-dimensional Magnetic Resonance Imaging of fossils across taxa. Biogeosciences. 2008;5(1):2541. doi: 10.5194/bg-5-25-2008
14. Englund M, Guermazi A, Gale D, Hunter DJ, Aliabadi P, Clancy M, Felson DT. Incidental meniscal findings on knee MRI in middle-aged and elderly persons. N Engl J Med. 2008 Sep 11;359(11):1108-15. doi: 10.1056/NEJMoa0800777.

15. Umap R, Anurag B, Bagale S, Shattari N. Evaluation of traumatic knee joint injuries with MRI. International Journal of Contemporary Medicine Surgery and Radiology 2018;3(3):C77-C81. doi: 10.21276/ijcmsr.2018.3.3.17

16. Jarvik JG, Dalinka MK, Kneeland JB. Hand injuries in adults. Semin Roentgenol. 1991 Oct;26(4):282-99. doi: 10.1016/0037-198x(91)90027-1.

17. Singh JP, Garg L, Shrimali R, Setia V, Gupta V. MR Imaging of knee with arthroscopic correlation in twisting injuries. Indian J Radiol Imaging. 2004;14(1):33-40.

18. Gupta K, Guleria M, Sandhu P, Galhotra R. Correlation of clinical, MRI and arthroscopic findings in diagnosing meniscus and ligament injuries at knee joint: A prospective study. J Orthop Allied Sci. 2013;1(1):2-6. doi: 10.4103/23192585.117379 . 